\title{
Forecasting Foreign Direct Investment to Zambia: A Time Series Analysis
}

\author{
Stanley Jere*, Bornwell Kasense, Obvious Chilyabanyama \\ Department of Mathematics and Statistics, Mulungushi University, Kabwe, Zambia \\ Email: *sjere@mu.ac.zm
}

How to cite this paper: Jere, S., Kasense, B. and Chilyabanyama, O. (2017) Forecasting Foreign Direct Investment to Zambia: A Time Series Analysis. Open Journal of Statistics, 7, 122-131. https://doi.org/10.4236/ojs.2017.71010

Received: October 17, 2016

Accepted: February 25, 2017

Published: February 28, 2017

Copyright (C) 2017 by authors and Scientific Research Publishing Inc. This work is licensed under the Creative Commons Attribution International License (CC BY 4.0).

http://creativecommons.org/licenses/by/4.0/

\section{(c) (i) Open Access}

\begin{abstract}
Three methods are considered in this paper: Simple exponential smoothing (SES), Holt-Winters exponential smoothing (HWES) and autoregressive integrated moving average (ARIMA). The best fit model was then used to forecast Zambia's annual net foreign direct investment (FDI) inflows from 1970 to 2014. Foreign direct investment is foreign capital investment to Zambia. Throughout the paper the methods are illustrated using Zambia's annual Net FDI inflows. A comparison of the three methods shows that the ARIMA (1, 1, 5 ) is the best fit model because it has the minimum error. Forecasting results give a gradual increase in annual net FDI inflows of about $44.36 \%$ by 2024 . Forecasting results plays a vital role to policy makers. Decision making, coming up with good policies and suitable strategic plans, depends on accurate forecasts. Zambian FDI policy makers can use the results obtained in this study and create suitable strategic plans to promote FDI.
\end{abstract}

\section{Keywords}

Foreign Direct Investment, Simple Exponential Smoothing, Holt-Winters

Exponential Smoothing, Autoregressive Integrated Moving Average,

Forecasting

\section{Introduction}

Forecasting is key in many fields of science. In this paper, three methods are of interest and they are: SES, HWES and ARIMA. Throughout the paper the methods are illustrated using Zambia's annual net FDI inflows. The best fit model is used to forecast Zambia's annual net foreign direct investment (FDI) from 1970 to 2014 .

SES method is a simple tool for forecasting time series data. Smoothing implies removing the unwanted noise so that the general path is created. This method is suitable for forecasting data without trend or seasonal pattern. It is basi- 
cally a recursive computing procedure [1]. The HWES method prediction items are obtained as a weighted average of past observed values where the weights reduce exponentially so that the values of recent observations contribute to the forecast more than the values of earlier observations [2]. ARIMA models can be used to produce forecasts for time series data. The ARIMA model has three parts. Not all parts are always necessary but it depends on the type of time series data at hand. The three parts are the autoregressive (AR), the integrated (I) and lastly, the moving average (MA). Assumption for the AR part of a time series data is that the observed value depends on some linear combinations of previous observed values up to some maximum lags plus error term. Assumption for the MA part of time series data is that the observed value is a random error term plus some linear combinations of previous random error terms up to some maximum lags [3].

FDI is foreign capital investment to a country. Foreign direct investment to a country results in increasing productivity, reducing unemployment, and increasing the use of technology. The need for FDI came as a result of shortages in domestic funding sources to finance development projects in developing countries. These developing countries realized that it is through FDI that they can achieve economic growth. According to [4], FDI excludes loan from international organizations, foreign governments, private commercial banks, stocks and bonds purchased by foreigners but it is an investment where managerial control is done by foreign investors. According to [5] FDI constitute activities such as decision making that are done by firms or groups of firms outside to the country of investment. Furthermore [6], FDI is defined as an investment that arises when the investor in the mother country invests in another country with an intension to have control on how to manage and run it.

Studies by [7] indicate that there is a positive relationship between FDI and economic growth. However, this positive relationship depends on human capital available in that economy. Furthermore, for countries with very low levels of human capital, then the direct effect of FDI is negative. They further argued that FDI result to competition with domestic investors and as a result the local and already existing businesses are affected negatively hence the weak positive relationship with Economic Growth. Studies by [8] indicate that, FDI inflows in developing countries led to "crowd in" other investment at macro level. Studies by [9] found that FDI inflows led to higher per capita GDP, economic growth rate, productivity growth, higher export in host country and increased backward, forward linkages with affiliates to multinationals.

The main goal for the Zambia government is to increase and sustain FDI inflows beyond the current levels to highly benefit the country. Zambian FDI inflows are mainly in copper and cobalt extraction, agricultural sector particular in horticulture and floriculture production, and in tourism. Firms or groups of firms from countries like United Kingdom and South Africa have traditionally been the main contributors of foreign direct investment though FDI inflow from other countries drastically increases. The net inflow to other countries is nega- 
tive indicating outflows that are FDI from those countries (inflows) are less than those from Zambia (outflows). However, the scope of this research is to discuss FDI inflows (Net) to Zambia. An analysis of the FDI flows by source country in 2012 shows that Canada (US $\$ 724.3$ million), South Africa (US $\$ 426.0$ million), the Netherlands (US \$262.2 million) and the United Kingdom (US \$227.2 million), were the major source countries of Zambia's FDI inflows, accounting for 94.7 per cent of total inflows, collectively. The other source countries are Switzerland (US \$166.9 million), China (US \$141.9 million), Nigeria (US \$94.6 million), Singapore (US \$62.0 million), Congo DR (US \$28.6 million) and France (US \$20.2 million) [10] [11] [12].

Forecasting results plays a vital role to policy makers. Decision making, coming up with good policies and suitable strategic plans, depends on accurate forecasts [13].

\section{Methodology}

\subsection{Simple Exponential Smoothing Model (SES)}

Simple exponential smoothing method involves smoothing out random fluctuations of time series data. The method is suitable for forecasting data without trend or seasonal pattern. This method gives past data weights known as smoothing constants that decrease exponentially with time. Below is the exponential smoothing model for time series data $X_{t}$ is shown below:

$$
\bar{X}_{t}=\alpha X_{t}+(1-\alpha) \bar{X}_{t-1}
$$

where $\alpha$ is the smoothing constant, $0<\alpha<1, t=1,2, \cdots, T, X_{t}$ is raw time series data and $\bar{X}_{t}$ is smoothed data or output.

The $h$-step-ahead forecast equation is

$$
\hat{X}_{t+h}=\bar{X}_{t}
$$

where $h=1,2,3, \cdots[13]$.

\subsection{Holt-Winters Exponential Smoothing Model (HWES)}

Holt-Winters exponential smoothing method is an extension of SES and uses a linear combination of the previous values of a series for generating and modeling future values. It is applies to time series data that has trend. Recent time series recordings are key to forecasting future values of a series. The model for time series data $X_{t}$ is as shown below:

$$
\begin{aligned}
& \bar{X}_{t}=\alpha X_{t}+(1-\alpha)\left(\bar{X}_{t-1}+b_{t-1}\right) \\
& 0<\alpha<1 \\
& b_{t}=\beta\left(\bar{X}_{t}-\bar{X}_{t-1}\right)+(1-\beta) b_{t-1} \\
& 0<\beta<1
\end{aligned}
$$

where $\alpha$ is the smoothing constant, $\beta$ is the trend smoothing constants, $X_{t}$ is raw data, $\bar{X}_{t}$ is smoothed data and $b_{t}$ is the trend estimates.

The $h$-step-ahead forecast equation is 


$$
\widehat{X}_{t+h}=\bar{X}_{t}+h b_{t} \quad([13])
$$

\subsection{Autoregressive Integrated Moving Average Model (ARIMA)}

Stochastic models attributed to Box-Jenkins known as the ARIMA have been found to be more efficient and reliable even for short term forecasting. Further, stochastic models are distribution-free as no assumptions are required about the data [14]. The ARIMA model consists of the following expressions called the order of autoregressive (AR) model $(p)$, differencing order $(d)$ and the order of moving average (MA) model $(q)$. The Box-Jenkin models are denoted by ARIMA $(p, d, q)$. " $P$ ' implies that the process need to undergo differentiation and when the modelling is done, the results undergo an integration process to produce forecasts and estimates. The expressions for MA, AR and ARMA are as follows:

AR model: $\widehat{X}_{t}=\sum_{i=1}^{p} \vartheta_{i} X_{t-i}+\varepsilon_{t}$

MA model: $\widehat{X}_{t}=\sum_{i=1}^{q} \varphi_{i} \varepsilon_{t-i}$,

ARMA model: $\widehat{X}_{t}=\sum_{i=1}^{p} \vartheta_{i} X_{t-i}+\varepsilon_{t}+\sum_{i=1}^{q} \varphi_{i} \varepsilon_{t-i}$

where $\vartheta_{t}$ is the autoregressive parameter at time $t, \varepsilon_{t}$ is the error term at time $t$ and $\varphi_{t}$ is the moving-average parameter at time $t[13]$.

\subsection{The Error Measures for Model-Selection}

The error measures are used to compare how well models fit the time series. According to [13], the best fit or forecasting model is one with minimal errors. The following error indicators were used in this paper:

\section{Results and Discussion}

The SES, HWES and ARIMA models are used to forecasting Zambia's annual Net Foreign direct investment (FDI) inflows from 1970 to 2014. $R$ is a widely used statistical software package for statistical analysis. It was used to come up with SES, HWES and ARIMA models. $R$ contains built-in functions that allow the user to determine model parameters spontaneously; the only requirement in this software is the time series data to be analysed. Using $R$, the SES model indicates that the parameter $\alpha=0.73$ is the best parameter value. The equation for this model thus takes the form

$$
\bar{X}_{t}=0.73 X_{t}+0.27 \bar{X}_{t-1}
$$

The HWES model indicate that the parameters $\alpha=0.31$ and $\beta=0.41$, giving us the following equations:

$$
\begin{aligned}
& \bar{X}_{t}=0.31 X_{t}+0.69\left(\bar{X}_{t-1}+b_{t-1}\right) \\
& b_{t}=0.41\left(\bar{X}_{t}-\bar{X}_{t-1}\right)+0.59 b_{t-1}
\end{aligned}
$$



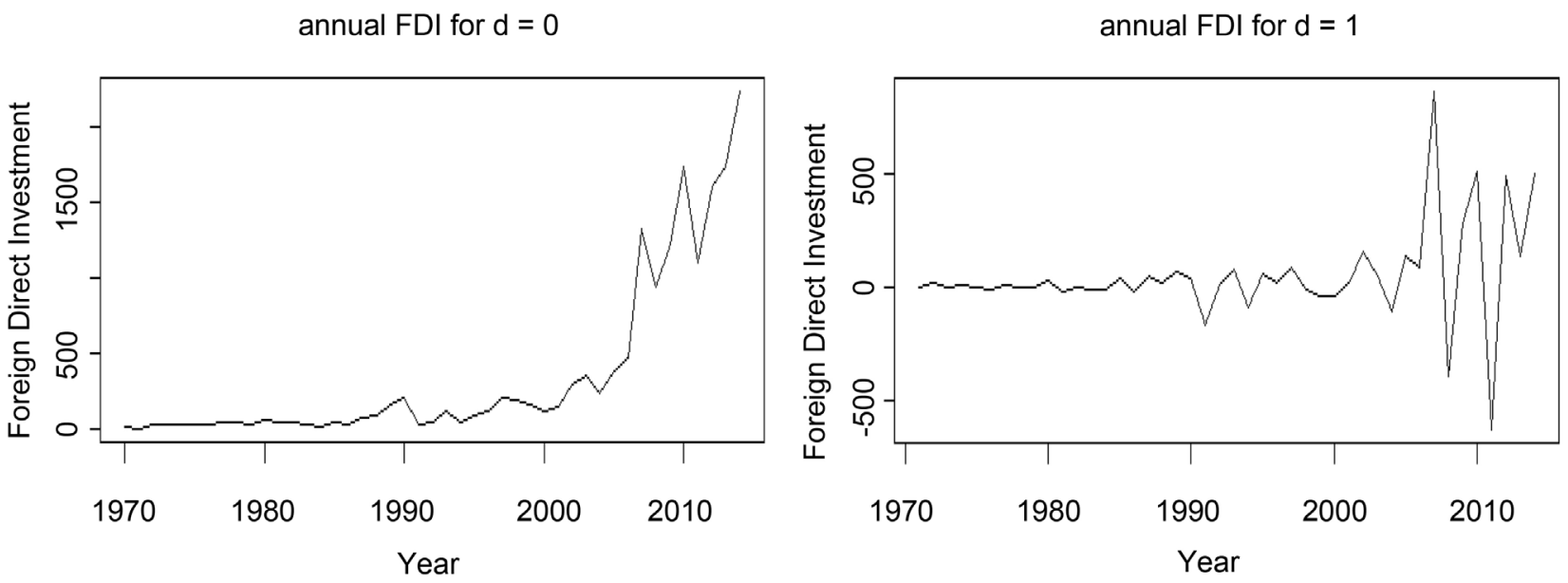

Figure 1. Time plots for $d=0$ and $d=1$. 
ACF for $d=0$

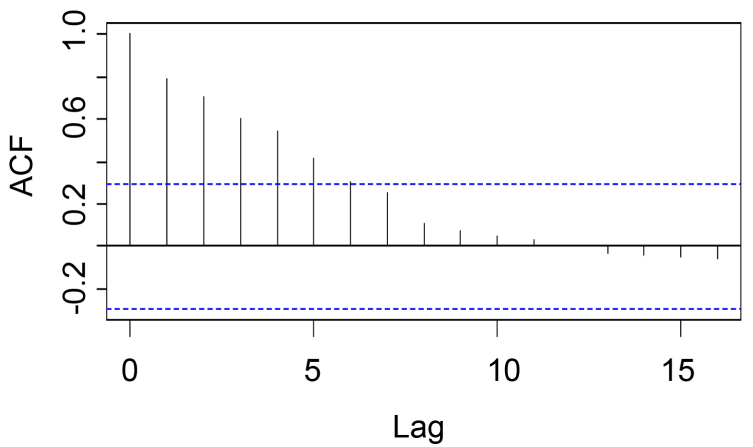

PACF for $d=0$

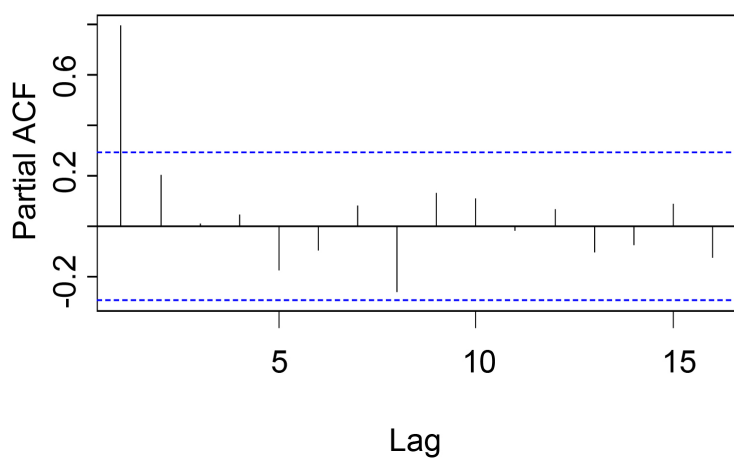

ACF for $d=1$

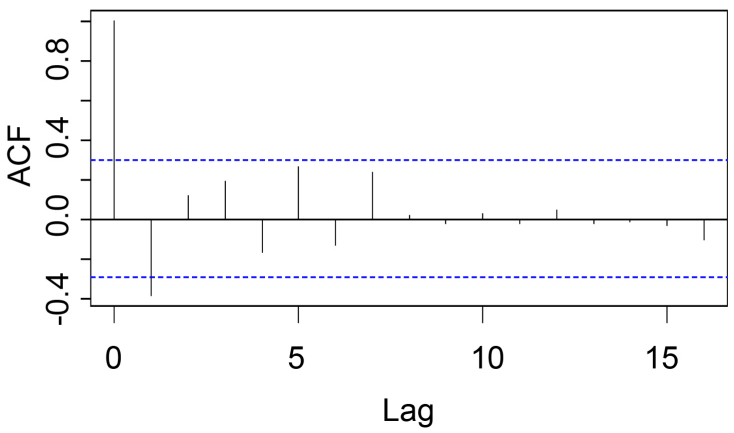

PACF for $d=1$

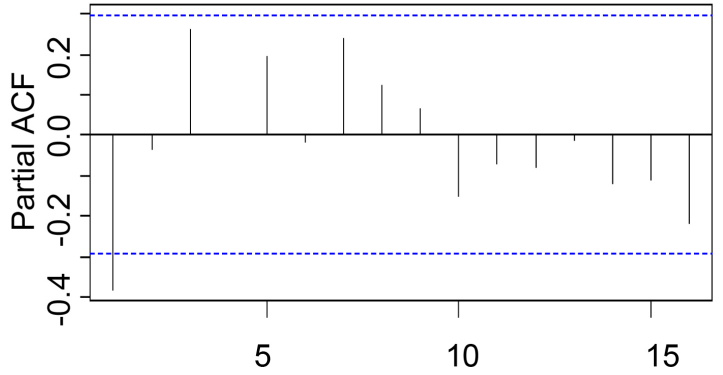

Lag

Figure 2. Plots of ACF and PACF for $d=0$ and $d=1$.

Table 1. The error indicators.

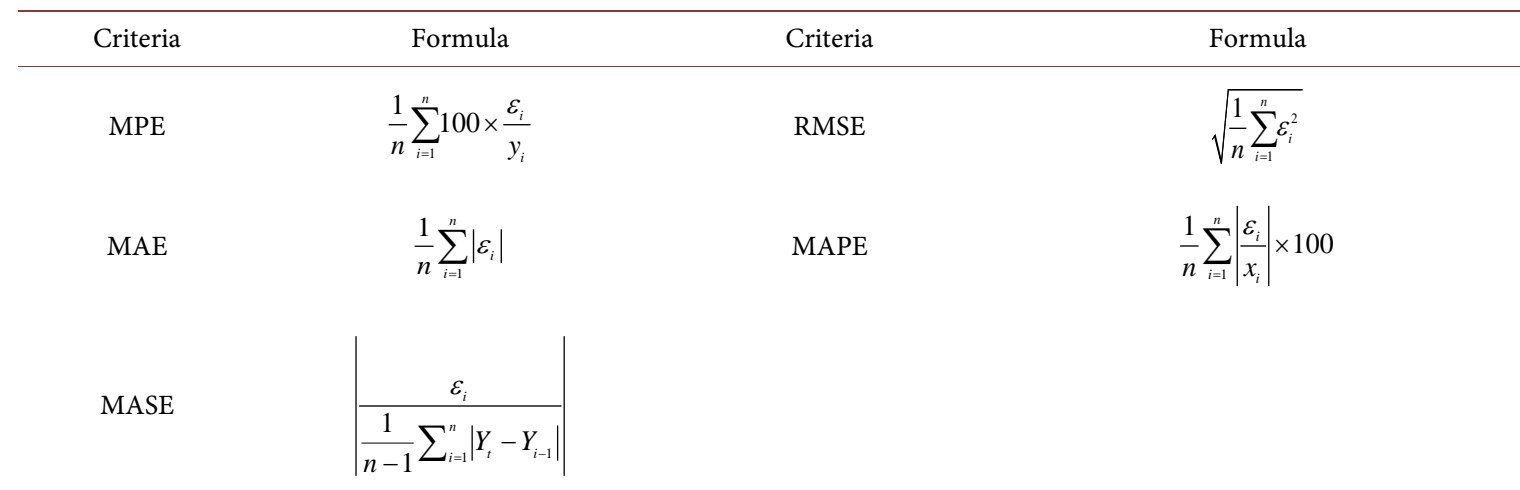

Table 2. The AIC statistics measures for selected ARIMA models.

\begin{tabular}{|c|c|c|c|c|c|c|c|c|}
\hline $\begin{array}{l}\text { TENTATIVE } \\
\text { MODEL }\end{array}$ & $\begin{array}{c}\text { ARIMA } \\
(1,1,5)\end{array}$ & $\begin{array}{c}\text { ARIMA } \\
(5,1,1)\end{array}$ & $\begin{array}{c}\text { ARIMA } \\
(1,1,3)\end{array}$ & $\begin{array}{c}\text { ARIMA } \\
(5,1,0)\end{array}$ & $\begin{array}{c}\text { ARIMA } \\
(0,1,2)\end{array}$ & $\begin{array}{l}\text { ARIMA } \\
(3,1,0)\end{array}$ & $\begin{array}{c}\text { ARIMA } \\
(1,1,0)\end{array}$ & $\begin{array}{l}\text { ARIMA } \\
(0,1,5)\end{array}$ \\
\hline AIC & 595.33 & 598.89 & 599.69 & 599.76 & 600.25 & 600.29 & 600.69 & 600.74 \\
\hline $\begin{array}{c}\text { TENTATIVE } \\
\text { MODEL }\end{array}$ & $\begin{array}{c}\text { ARIMA } \\
(0,1,3)\end{array}$ & $\begin{array}{c}\text { ARIMA } \\
(4,1,0)\end{array}$ & $\begin{array}{c}\text { ARIMA } \\
(0,1,1)\end{array}$ & $\begin{array}{c}\text { ARIMA } \\
(0,1,4)\end{array}$ & $\begin{array}{c}\text { ARIMA } \\
(2,1,0)\end{array}$ & $\begin{array}{c}\text { ARIMA } \\
(1,1,1)\end{array}$ & $\begin{array}{c}\text { ARIMA } \\
(2,1,2)\end{array}$ & \\
\hline AIC & 601.55 & 601.68 & 602.01 & 602.48 & 602.67 & 602.68 & 603.09 & \\
\hline
\end{tabular}

therefore be written as 


$$
\widehat{X}_{t}=0.830 X_{t-1}-1.324 \varepsilon_{t-1}+0.404 \varepsilon_{t-2}+0.529 \varepsilon_{t-3}-0.827 \varepsilon_{t-4}+0.634 \varepsilon_{t-5}
$$

Step 4: Diagnostic Checking

Goodness of fit for time series models involves testing if the model residuals form a white noise process. It is through diagnostic checks that a model can be declared statistically adequate and thereafter can be used to forecast. According to [14], if the diagnostic tests fails a new process (cycle) of identification, estimation and diagnosis is done until the best fit model is found.

The Plots of ACF, Normal Q-Q and Histogram of Residuals show that the residual are a white noise process. Thus, diagnostic check for an ARIMA $(1,1,5)$ model in Figure 3 indicates that the model is good (best fit).

The results in Table 4 show that the ARIMA $(1,1,5)$ model performed better than the SES and HWES models on FDI data for Zambia due to the minimal error. Hence, this model was picked for forecasting.

\section{Forecasts}

Forecasting results plays a vital role to policy makers in creating good policies and coming up with suitable strategic plans on FDI. R output of ARIMA $(1,1,5)$ forecasts for the next 10 years of annual net Zambia's FDI's inflow is shown in Table 5 .

Table 5 shows ten year forecasts for FDI using $\operatorname{ARIMA}(1,1,5)$. Trajectory of

ACF of Residuals

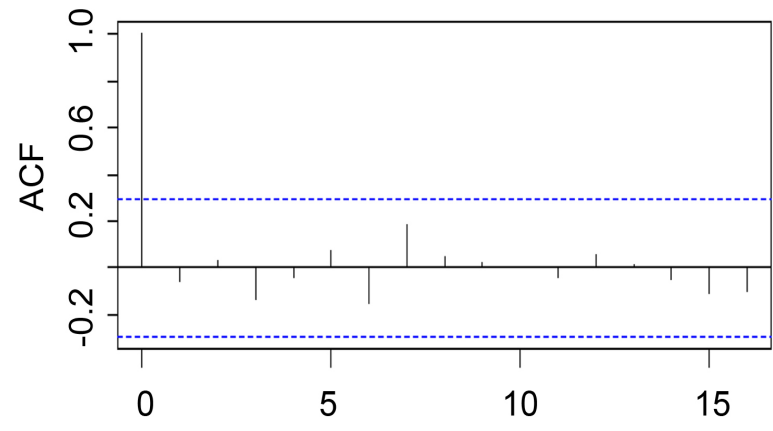

Lag
Normal Q-Q Plot

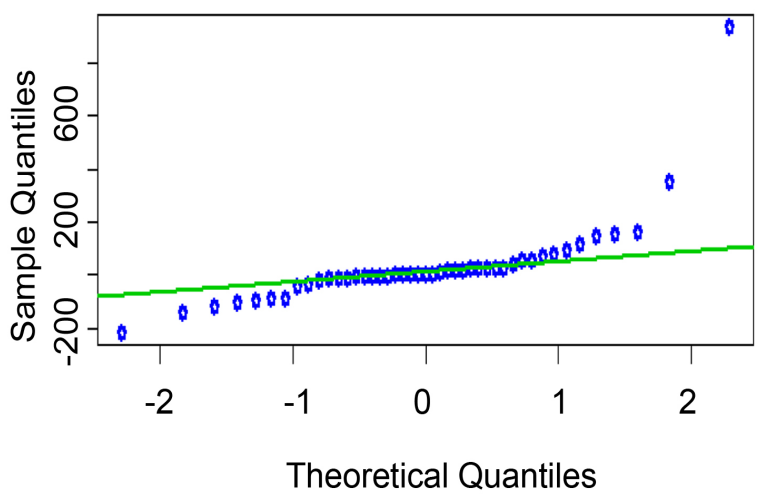

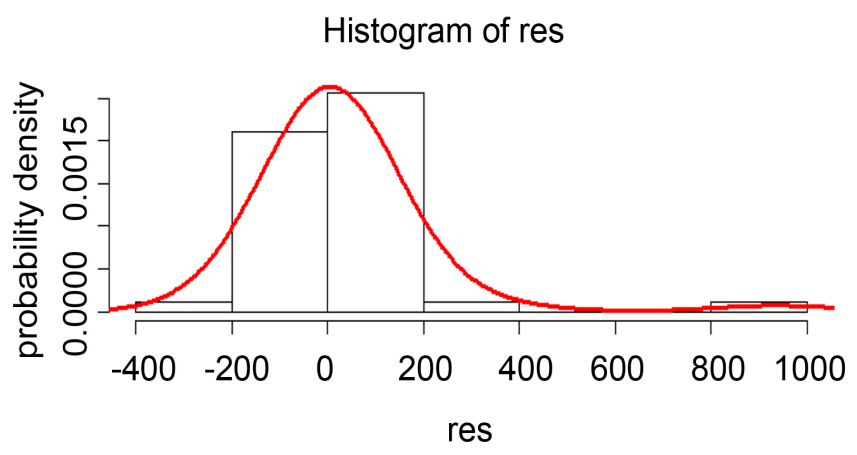

Figure 3. Plots of ACF, Normal Q-Q and histogram of residuals. 
forecasts in the period from 2014 to 2024 is shown in Figure 4. Forecasting results give a gradual increase in annual net FDI inflows of about $44.36 \%$ by 2024 .

\section{Discussion}

Forecasting is key to every field of science. ARIMA $(1,1,5)$ can be used to forecast the annual net inflows of FDI to Zambia. This model can be used for both

Table 3. Estimate of ARIMA $(1,1,5)$.

\begin{tabular}{ccc}
\hline Variable & Coefficient & $p$-value \\
\hline Constant & & 0.000000036 \\
\hline AR (1) & 0.830 & 0.000000000060 \\
MA (1) & -1.324 & 0.10 \\
MA (2) & 0.404 & 0.019 \\
MA (3) & 0.529 & 0.0013 \\
MA (4) & -0.827 & 0.00015 \\
MA (5) & 0.634 & 0 \\
\hline
\end{tabular}

Note: ${ }^{\star} p$ value $<0.05$.

Table 4. Measure of the errors for the three models.

\begin{tabular}{cccc}
\hline Measure of accuracy & SES & HWES & ARIMA $(1,1,5)$ \\
MPE & -4.573 & 266.981 & 165.380 \\
RMSE & 213.696 & 133.025 & 76.74 \\
MAE & 111.912 & 2.659 & -9.478 \\
MAPE & 45.413 & 47.617 & 39.960 \\
MASE & 0.929 & 1.103 & 0.637 \\
\hline
\end{tabular}

Table 5. R output of ARIMA $(1,1,5)$ forecasts for the next 10 years.

\begin{tabular}{cccccc}
\hline Year & $\begin{array}{c}\text { Point } \\
\text { Forecast }\end{array}$ & Lo 80 & Hi 80 & Lo 95 & Hi 95 \\
\hline 2015 & 2353.979 & 2135.315 & 2572.644 & 2019.561 & 2688.398 \\
2016 & 2442.925 & 2194.337 & 2691.512 & 2062.743 & 2823.106 \\
2017 & 2757.575 & 2482.147 & 3033.004 & 2336.343 & 3178.807 \\
2018 & 2665.618 & 2304.685 & 3026.552 & 2113.619 & 3217.618 \\
2019 & 2806.015 & 2415.494 & 3196.537 & 2208.764 & 3403.267 \\
2020 & 2922.545 & 2477.628 & 3367.463 & 2242.103 & 3602.988 \\
2021 & 3019.266 & 2500.801 & 3537.732 & 2226.341 & 3812.191 \\
2024 & 3099.545 & 2495.403 & 3703.686 & 2175.590 & 4023.499 \\
\hline
\end{tabular}




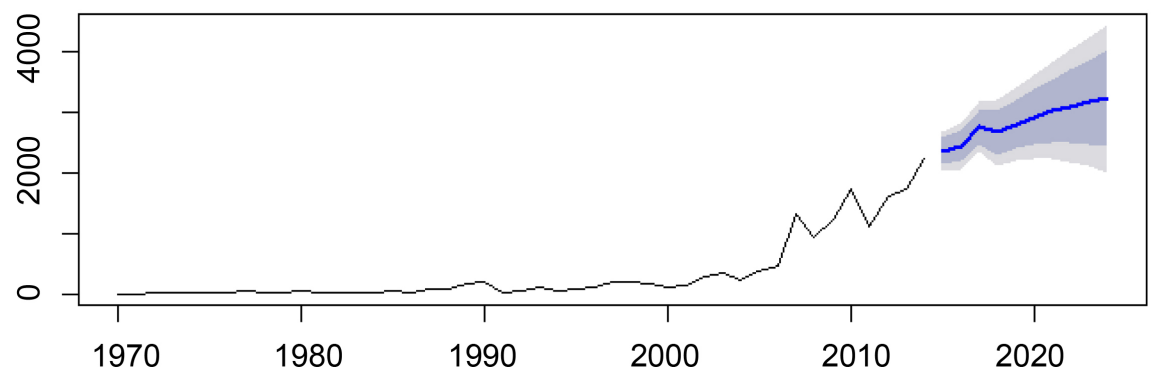

Figure 4. $R$ output of ARIMA $(1,1,5)$ forecasts for the next 10 years.

short and long term forecasting. Best strategies can only be created with accurate forecasting results. Studies have shown that FDI affects the growth of GDP. Therefore, the importance of FDI is acknowledged world over. FDI also helps diversify the country's economy (through job creation and increase in productivity), increase export in host country, improve efficiency and have technological spillovers on the already existing firms.

\section{Conclusion}

Three models of univariate time-series analysis were considered in this study: SES, HWES and ARIMA models. The best fit of the three models used in this study was picked based on the model indicating minimum errors. The ARIMA $(1,1,5)$ showed smallest error than that of the SES or HWES models. Forecasting results give a gradual increase in annual net FDI inflows of about $44.36 \%$ by 2024. Policy makers use accurate forecasts to come up good policies. Therefore, the Zambian government should use such forecasts in formulating policies and making strategies that will promote FDI industry. Future research should go further and consider non-linear models such as Autoregressive Conditional Heteroscedasticity (ARCH), Generalized Autoregressive Conditional Heteroscedasticity (GARCH).

\section{Acknowledgements}

The authors are thankful to Zambia Development Agency (ZDA) for providing time series data on FDI. Many thanks also go to the Dean, School of Science, Engineering and Technology Dr Douglas Kunda for the encouragements. Not forgetting Mulungushi University for making it possible through provision of resources to come up with this research work. Also many other colleagues who made good comments on this paper.

\section{References}

[1] Fried, R. and George, A.C. (2014) Exponential and Holt-Winters Smoothing. International Encyclopedia of Statistical Science, Springer, Berlin Heidelberg. http://ceur-ws.org/Vol-1353/paper_13.pdf

[2] Chatfield, C. (1978) The Holt-Winters Forecasting Procedure. Applied Statistics, 27, 
264-279. https://doi.org/10.2307/2347162

[3] Box, G.E. and Jenkins, G.M. (1994) Time Series Analysis: Forecasting and Control. Prentice Hall, Englewood Cliffs.

http://bookmarksland.com/download/time-series-analysis-forecasting-and-control4th-edition-free.pdf

[4] Fu, J. (2000) Institutions and Investments: Foreign Direct Investment in China during an Era of Reforms. University of Michigan Press, Ann Arbor.

https://www.press.umich.edu/16284/institutions_and_investments https://doi.org/10.3998/mpub.16284

[5] Hayter, R. (1997, Ongoing) The Dynamics of Industrial Location: The Firm, the Factory and the Production System. Notes of the Book

[6] Abdul Hasan, S. and Al-Samarrai, H. (1998) A Seminar on Foreign Investment Justification and Notification. Bayt al-Hikma, Baghdad.

http://www.ijmbs.com/Vol5/3/8-abhijit-biswas.pdf

[7] Borensztein, E., De Gregorio, J. and Lee, J.-W. (1998) How Does Foreign Direct Investment Affect Economic Growth? Journal of International Economics, 45, 115 135. https://doi.org/10.1016/S0022-1996(97)00033-0

[8] Tybout, J.R. (2000) Manufacturing Firms in Developing Countries: How Well Do They Do and Why? Journal of Economic Literature, XXXVIII, 11-44.

https://doi.org/10.1257/jel.38.1.11

[9] Markusen \& Venables (1999) Foreign Direct Investment as a Catalyst for Industrial Development. European Economic Review, 43, 335-356. https://doi.org/10.1016/S0014-2921(98)00048-8

[10] ZDA (2016) Zambia Development Agency, Lusaka, Zambia.

[11] BOZ (2013) Bank of Zambia Annual Report, Lusaka, Zambia.

[12] C.S.O. (2015) National Accounts. Statistical Bulletins, No. 2, 3, 5 and 7, Lusaka, Zambia.

[13] Tularam, G.A. and Saeed, T. (2016) Oil-Price Forecasting Based on Various Univariate Time-Series Models. American Journal of Operations Research, 6, 226-235. https://doi.org/10.4236/ajor.2016.63023

[14] Siluyele, I. and Jere, S. (2016) Using Box-Jenkins Models to Forecast Mobile Cellular Subscription. Open Journal of Statistics, 6, 303-309. https://doi.org/10.4236/ojs.2016.62026

[15] Dobre, I. and Alexandru, A. (2008) Modelling Unemployment Rate Using BoxJenkins Procedure. Journal of Applied Quantitative Methods, 3, 156-166.

[16] Wei, W. (1990) A Time Series Analysis: Univariate and Multivariate Methods. Addison Wesley Publishing Company, Inc., New York. 
Submit or recommend next manuscript to SCIRP and we will provide best service for you:

Accepting pre-submission inquiries through Email, Facebook, LinkedIn, Twitter, etc. A wide selection of journals (inclusive of 9 subjects, more than 200 journals)

Providing 24-hour high-quality service

User-friendly online submission system

Fair and swift peer-review system

Efficient typesetting and proofreading procedure

Display of the result of downloads and visits, as well as the number of cited articles Maximum dissemination of your research work

Submit your manuscript at: http://papersubmission.scirp.org/

Or contact ojs@scirp.org 